\title{
Relationship between prenatal care and the outcome of pregnancy in low-risk pregnancies
}

\author{
Tehereh Ashraf-Ganjoei ${ }^{1}$, Fatemeh Mirzaei $^{2^{*}}$, Fatemeh Anari-Dokht ${ }^{3}$ \\ ${ }^{1}$ Departement of obstetric \& gynecology, Shahid Behshtei University, Tehran, Iran;
${ }^{2}$ Departement of obstetric \& gynecology, Physiology research center, Kerman University, Kerman, Iran;
${ }^{3}$ Afzalipour Hospital, Kerman University of Medical Sciences, Kerman, Iran;
E-mail: " $m$ mirzaie fatemeh@yahoo.com
}

Received 30 May 2011; revised 22 August 2011; accepted 30 August 2011.

\begin{abstract}
Introduction: This study was conducted to evaluate the relationship between prenatal care and outcome of pregnancy. Method: This is a cross-sectional study on 210 pregnant women referring to Afzalipour Hospital for their labor, consisting of 140 women with adequate care and 70 with inadequate care. The outcome of pregnancy for mother and newborn was compared between the two groups. Data were analyzed using SPSS software version 15. P value $\leq \mathbf{0 . 0 5}$ was considered as significant and the power of statistical test was $80 \%$. Findings: The findings indicate that the age of women with inadequate care was lower compared to those receiving adequate care $(p=$ 0.003). Furthermore, women with inadequate care had lower education $(p=0.00007)$ and their prenatal care started in more advanced gestational ages ( $p=$ 0.0003). Neonates born to women with inadequate care tended to have lower birth weights $(p=0.05)$ and higher rates of admission to $\operatorname{NICU}(p=0.02)$. Conclusion: Our findings indicate that women with lower age and education received less prenatal care and adequate prenatal care results in better birth weights and decreased rate of admission in NICU.
\end{abstract}

Keywords: Prenatal Care; Maternal Complications; Neonatal Complications

\section{INTRODUCTION}

Pregnancy constitutes one of the most sensitive periods of a woman's life, both physically and mentally [1]. Prenatal care has a history of more than 100 years; it is currently among the most important services provided by the healthcare system and its use is gaining increasing popularity [2]. The purpose of prenatal care is to deliver a healthy newborn without jeopardizing the mother's health [3].Prenatal care and appropriate fetal monitoring lead to timely interventions for prevention of preterm labor and premature neonates. Moreover, prenatal care may play a pivotal role to facilitate the pregnant woman transferring to a properly-equipped labor center in a timely manner [4]. If performed systematically and regularly, it may considerably reduce mortality and complications in mothers and newborns [5]. Healthcare experts have concluded that prenatal care is a cost-efficient investment. Therefore, it appears essential to provide access to prenatal care from the early onset of pregnancy [6]. However In a randomized clinical trial in the United States in 1996, no considerable increase in preterm labor, preeclampsia, C-section and low birth weight was observed in women who had received less prenatal care [7]. Since there is no definite scientific basis for improving the impact of prenatal care on outcome of pregnancy [1], as well as the fact that certain risk factors, modifiable through prenatal care, may be more frequent in developing countries where few studies have been conducted [8], we undertook this study to determine the impact of prenatal care on maternal and fetal outcome.

\section{METHODS}

A cross-sectional study was performed on women referring to Afzalipour Hospital over a 1-year period from 2009 to 2010. Afzalipoor hospital Institutional Research Review Board approved the study; furthermore, the study was carried out under the Health Ministry Ethics protocols.

Data were collected using data-recording sheets through interviews and studies of medical files. All patients received adequate information regarding the study and they all expressed their informed consent in written forms.

Patients with a systemic disease, such as diabetes, hypertension, epilepsy, lupus, cancer, renal disease or any other systemic disease, as well as those considering as cigarette smokers or narcotics users were excluded 
from the study. The number of prenatal cares for each person was determined and women were categorized as either receiving adequate care or inadequate care (defined as less than 5 visits for gestational ages of less than 37 weeks or less than 8 visits for gestational ages of 37 weeks or beyond) [8]. The outcome of pregnancy, including gestational age, birth weight, Apgar score, route of delivery, need for NICU and occurrence of preeclampsia, gestational diabetes and postpartum hemorrhage were evaluated and compared between the two groups.

Gestational age was determined by the patient's last menstrual period (LMP) and, when available, confirmed by the first trimester ultrasound. The sample size was determined based on previous studies and the study was performed on 210 women referring to Afzalipour Hospital for their labor, consisting of 140 women with adequate care and 70 with inadequate care.

After determination of descriptive statistics (central and dispersion indices), data were analyzed using SPSS software version 15 . The Chisquare test was used to compare the outcome of pregnancy between the two groups. $\mathrm{P}$ value $\leq 0.05$ was considered as significant and the power of statistical test was $80 \%$.

\section{RESULTS}

210 pregnant women composed of 140 receiving adequate care and 70 receiving inadequate care were studied. The overall mean age was $26.65 \pm 0.4$ years, with the mean age of $24.9 \pm 0.7$ years for women receiving inadequate group and $27.52 \pm 0.48$ years for those receiving adequate care, indicating a significant difference $(p=$ 0.003) (Table 1).

$101(48.09 \%)$ of women were educated less than a high school diploma, 79 (37.61\%) were high school graduates and $30(14.28 \%)$ had university level of education. The relationship between education and type of prenatal care is illustrated in Table 1.

193 (91.9\%) of women were housewives, 13 (6.19\%) were clerks and $4(1.9 \%)$ worked in the private sector. In the group with adequate prenatal care, there were 126 (90\%) housewives, $12(8.57 \%)$ clerks and $2(1.42 \%)$ workers in private sector. In the group with inadequate prenatal care, there were $67(95.71 \%)$ housewives, 1 $(1.42 \%)$ clerk, and $2(2.58 \%)$ worked in the private sector $(\mathrm{p}=0.4)($ Table 1$)$.

The mean gestational age of onset of cares was 12.59 \pm 1 weeks for the group with inadequate care and $8.39 \pm$ 0.3 weeks for the other group $(\mathrm{p}=0.05)$ (Table 1).

The mode of delivery in women consisted of 82 (39.04\%) NVD and 128 (60.85\%) Cesarean section. The relationship between prenatal care and route of delivery is showed in Table 2.
Regarding the gestational age, there were 51 (24.28\%) preterm, $130(61.9 \%)$ term l, and $24(11.42 \%)$ post-date delivery. There were no significant differences among two groups according to the gestational age at delivery $(\mathrm{P}=0.3)$.

The mean birth weight of all neonates was $2891.19 \pm$ $45.07 \mathrm{~g}$; the figures for the group with adequate care and the group with inadequate care were $2958.21 \pm 49.2 \mathrm{~g}$ and $2757.14 \pm 90.9 \mathrm{~g}$, respectively, indicating a significant difference $(\mathrm{p}=0.05)$ (Table 2).

The mean $1^{\text {st }}$ minute Apgar score was $8.76 \pm 0.71$ for those with adequate care and $8.53 \pm 0.17$ for those with inadequate care, indicating no significant difference $(p=$ 0.2) (Table 2). The mean $5^{\text {th }}$ minute Apgar scores for the adequate and inadequate care groups were $9.81 \pm 0.6$ and $9.63 \pm 0.16$ respectively, indicating no significant difference $(\mathrm{p}=0.3)$ (Table 2).

$29(13.8 \%)$ newborns were admitted to NICU, consisting of $15(21.43 \%)$ in the inadequate care group and $14(12.14 \%)$ in the adequate care group (Table 2).

There were 17 cases of gestational diabetes in our study, with $15(88.23 \%)$ of them in the adequate care group and $2(11.76 \%)$ in the inadequate care group $(\mathrm{p}=$ 0.05) (Table 3).

Early postpartum hemorrhage was observed in $3(1.42 \%)$ patients, all of them were in the adequate care group $(\mathrm{p}=$ $0.2)$. preeclampsia was observed in $18(8.57 \%)$ of patients, including $11(61.11 \%)$ in the adequate care group and $7(38.88 \%)$ in the inadequate care group $(\mathrm{p}=0.6)$ (Table 3).

\section{DISCUSSION}

Our findings indicate that the mean age and education of women with inadequate prenatal care are lower compared to those receiving adequate prenatal care. According to a study by Fekrat (1998), higher age and lower education decreased the likelihood of referral for prenatal care [9]. Similarly, Kulmala et al. reported that illiteracy and lower levels of education are among major reasons for not referring regularly for receiving prenatal cares [10]. In our study, only 17 women were employed, therefore, no significant relationship was found between the employment of pregnant women and level of care received. 14 of the employed women had received prenatal care and this indicates that employment may have a positive effect on referral of pregnant women for prenatal care. In this study, the time of the initiation of prenatal care in women with adequate care was earlier; a finding consistent with previous studies which indicated that the most common cause of not referring for prenatal care was unawareness of pregnancy. Regarding the gestational age, the majority of women had term labor, followed by preterm, post-date and post term labor, in de- 
Table 1. Primary and Demographic characteristics of patients.

\begin{tabular}{|c|c|c|c|c|}
\hline Variable & Total & Inadequate Care & Adequate Care & $\mathrm{P}$ Value \\
\hline Maternal Age & $26.54 \pm 0.4$ & $24.09 \pm 0.7$ & $27.52 \pm 0.48$ & 0.003 \\
\hline \multicolumn{5}{|l|}{ Maternal Education } \\
\hline Below High School Diploma & $101(48.1)$ & $48(68.5 \%)$ & $53(37.8 \%)$ & 0.00007 \\
\hline High School Diploma & $79(37.6)$ & $17(35.4 \%)$ & $62(44.2 \%)$ & \\
\hline University & $30(14.3)$ & $5(7.1 \%)$ & $25(17.8 \%)$ & \\
\hline \multicolumn{5}{|l|}{ Maternal Occupation } \\
\hline housewives & $193(91.9 \%)$ & $67(95.71 \%)$ & $126(90 \%)$ & 0.4 \\
\hline Clerk & $13(6.19 \%)$ & $1(1.42 \%)$ & $12(8.57 \%)$ & \\
\hline Private Sector & $4(1.9 \%)$ & $2(2.85 \%)$ & $2(1.42 \%)$ & \\
\hline Onset of Prenatal Care & $9.97 \pm 0.44$ & $12.59 \pm 1$ & $8.39 \pm 0.3$ & 0.0003 \\
\hline
\end{tabular}

Table 2. Comparison of outcome of pregnancy between adequate and inadequate care groups.

\begin{tabular}{|c|c|c|c|c|}
\hline $\begin{array}{l}\text { Outcome of Pregnancy } \\
\text { (Number/Percent) }\end{array}$ & Total & Inadequate Care & Adequate Care & P Value \\
\hline Gestational Age & & & & 0.3 \\
\hline Preterm & $51(24.28 \%)$ & $19(27.14 \%)$ & $32(22.85 \%)$ & \\
\hline Term & $130(61.9 \%)$ & $43(61.4 \%)$ & $87(62.14 \%)$ & \\
\hline Post-date & $24(11.45 \%)$ & $7(10 \%)$ & $17(12.14 \%)$ & \\
\hline Postterm & $5(2.38)$ & $1(1.42 \%)$ & $4(2.85 \%)$ & \\
\hline Mode of Delivery & & & & 0.05 \\
\hline Repeated C/S & $57(27.14 \%)$ & $16(22.85 \%)$ & $41(29.28 \%)$ & \\
\hline $\mathrm{C} / \mathrm{S}$ & $71(31.86 \%)$ & $19(27.15 \%)$ & $52(37.14 \%)$ & \\
\hline NVD & $82(39 \%)$ & $35(50 \%)$ & $52(37.14 \%)$ & \\
\hline Birth Weight & $2891.19 \pm 45.07$ & $2757 \pm 90.9$ & $2958.21 \pm 49.2$ & 0.05 \\
\hline $1^{\text {st }}$ minute Apgar & $8.68 \pm 0.07$ & $8.53 \pm 0.17$ & $8.76 \pm 0.76$ & 0.2 \\
\hline $5^{\text {th }}$ minute Apgar & $9.75 \pm 0.69$ & $9.63 \pm 0.16$ & $9.81 \pm 0.06$ & 0.3 \\
\hline NICU Admission & $29(13.80)$ & $15(21.43 \%)$ & $14(12.14 \%)$ & 0.02 \\
\hline
\end{tabular}

Table 3. Comparison of outcome or pregnancy between adequate and inadequate care groups.

\begin{tabular}{ccccc}
\hline $\begin{array}{c}\text { Maternal Complications } \\
\text { (Number/Percent) }\end{array}$ & Total & Inadequate Care & Adeguate Care & P Value \\
\hline Gestational Diabetes & $17(8 \%)$ & $2(2.85 \%)$ & $15(10.7 \%)$ & 0.05 \\
Early Postpartum Hemorrhage & $3(1.4 \%)$ & $0(0 \%)$ & $3(2.1 \%)$ & 0.2 \\
preeclampsia & $18(8.5 \%)$ & $7(10 \%)$ & $11(7.8 \%)$ & 0.6 \\
\hline
\end{tabular}

creasing order of frequency, indicating no significant difference between the two groups. In study, Vintzileos et al. (2002) delay in initiating prenatal care or waiving it will be associated with complications of pregnancy including premature rupture of membranes and post term pregnancy [11]. Apparently, our study differs from the latter as we have not exclusively dealt with preterm or post term housewives women. No significant increase in preterm labor in women who had received less prenatal care $(\mathrm{p}=0.19)$ has been reported by McDuffie et al. [7]. Regarding the route of delivery, the rate of vaginal de- livery was lower in women who had received adequate prenatal care which may be due to the more intense prenatal care in this group. In addition, in our study the rate of previous $\mathrm{C}$-section in women with adequate care was higher that is a reason for their higher rate of $\mathrm{C}$-section. In a study in 1996, prenatal care did not affect the rate of C-section considerably [7].

In our study, gestational diabetes was more frequent in women with adequate prenatal care which may be due to their higher rate of referral to prenatal care centers. However, the rates of preeclampsia and early postpartum 
hemorrhage were not significantly different between the two groups, although we did not compare the severity of preeclampsia between the groups and it requires further studies. Similarly, a study in 1996, the group with inadequate care did not have a significant increase in the rate of preeclampsia $(p=0.74)$ [7].

In the present study, the birth weight of newborn with adequate prenatal care was significantly higher. In a study Hueston et al, indicated that the prevalence of low birth weight was lower in newborns who had received prenatal care from the first trimester compared to those who had received the care in the second and third trimester [5]. Goldani (2004) considers the impact of prenatal care on improving birth weight as the result of prevention of newborns with SGA, better nutrition during pregnancy and reduced cigarette smoking in women with adequate prenatal care [8].

The present study reported that, the rate of NICU admission was lower in the group with adequate prenatal care. Nevertheless, the $1^{\text {st }}$ and $5^{\text {th }}$ minute Apgar scores were not significantly different between the two groups. However, in the study by Boss et al, sufficient prenatal care was associated with improved neonatal mortality, birth weight, and Apgar scores [12].

\section{ACKNOWLEDGEMENTS}

The authors wish to express their gratitude to the Deputy of Research at Kerman University of Medical Sciences for their sponsorship.

\section{REFERENCES}

[1] Katz, V.L. (2008) Prenatal care. In: Gibbs, R.S., Karlan, B.Y., Haney, A.F., Nygaard, I. Danforths Obstetrics \& Gynecology, China Philadelphia, 1-21.

[2] Alexander, G.R. and Kotelchuck, M. (2001) Assessing the role and effectiveness of prenatal care: History, challenges, and directions for future research. Public Health Report, 116, 306-316.
[3] Cunningham, F.G., Gant, N. F., Leveno, K.J., Gilstrap, L.C., Hauth, J.C. and Wenstrom, K.D. (2001) Williams obstetrics, 21th Edition. McGraw-Hill, New York, 224-225.

[4] Oboro, V.O., Tabowei, T.O., Jemikalajah, J.J., Bosah, J.O. and Agu, D. (2003) Pregnancy outcomes among nulliparous teenagers in suburban Nigeria. Journal of Obstetrics and Gynaecology, 23, 166-169. doi:10.1080/0144361031000074718

[5] Chang, J., Elam-Evans, L.D. and Berg, C.J., et al. (2003) Pregnancy-related mortality surveillance-United States, 1991-1999. MMWR Surveillance Summaries, 52, 1-8.

[6] Hueston, W.J., Gilbert, G.E., Davis, L. and Sturgill, V. (2003) Delayed prenatal care and the risk of low birth weight delivery. Journal of Community Health, 28, 199 208. doi:10.1023/A:1022908307844

[7] McDuffie, R.S.J., Beck, A., Bischoff, K., Cross, J. and Orleans, M. (1996). Effect of frequency of prenatal care visits on perinatal outcome among low-risk women. A randomized controlled trial. Journal of the American Medical Association, 275, 847-851. doi:10.1001/jama.275.11.847

[8] Goldani, M.Z., Barbieri, M.A., Silva, A.A. and Bettiol, H. (2004) Trends in prenatal care use and low birthweight in southeast Brazil. American Journal of Public Health, 100, 1366-1371. doi:10.2105/AJPH.94.8.1366

[9] Fekrat, M., Kashanian, M. and Saberi, Z. (2004) A study of the factors influencing the lack of referral of pregnant women for prenatal care. Journal of Iran Uni- versity of Medical Sciences, 42, 605-610.

[10] Kulmala, T., Vaahtera, M. and Ndekha, M., et al. (2000) Socio economic support for good health in rural Malawi. East African Medicine Journal, 77, 168-171.

[11] Vintzileos, A.M., Ananth, C.V., Smulian, J.C., Scorza, W.E., Knuppel and R.A. (2002) The impact of prenatal care on neonatal deaths in the presence and absence of antenatal high-risk conditions. American Journal of Obstetrics and Gynecology, 186, 1011-1016. doi:10.1067/mob.2002.122446

[12] Boss, D.J., Timbrook, R.E. (2001) Fort wayne medical education research group, Clinical obstetric outcomes related to continuity in prenatal care. Journal of the American Board of Family Practice, 14, 418-423. 